\title{
"I can be a mum or a professional, but not both": what women say about their experiences of juggling paid employment with motherhood
}

\author{
Jacqueline Coombe ${ }^{1 *}$, Deb Loxton ${ }^{1}$, Leigh Tooth ${ }^{2}$, Julie Byles ${ }^{1}$ \\ ${ }^{1}$ Research Centre for Generational Health and Ageing, University of Newcastle, Australia \\ ${ }^{2}$ Faculty of Medicine, School of Public Health, The University of Queensland, Brisbane, \\ Australia
}

*Correspondence to: Jacqueline Coombe, Sexual Health Unit, Centre for Epidemiology and Biostatistics, Melbourne School of Population and Global Health, Level 3, 207 Bouverie St, Carlton, The University of Melbourne, Victoria 3010 Australia

Email: jacqueline.coombe@unimelb.edu.au

Funding details: The research on which this paper is based was conducted as part of the Australian Longitudinal Study on Women's Health by the University of Queensland and the University of Newcastle. We are grateful to the Australian Government Department of Health for funding. There was no involvement from the funders in the preparation of this article, the analysis and interpretation of the data, the writing of the report or the decision to submit this article for publication.

Disclosure statement: The authors report no conflict of interest

Data statement: Information regarding ALSWH data can be found here: http://www.alswh.org.au/for-researchers

Acknowledgements: The research on which this paper is based was conducted as part of the Australian Longitudinal Study on Women's Health by the University of Queensland and the University of Newcastle. We are grateful to the Australian Government Department of Health for funding and to the women who provided the survey data.

Word count: 7582 words

Author Blurbs:

This is the author manuscript accepted for publication and has undergone full peer review but has not been through the copyediting, typesetting, pagination and proofreading process, which may lead to differences between this version and the Version of Record. Please cite this article as doi: $10.1002 / \mathrm{AJS} 4.76$

This article is protected by copyright. All rights reserved 
Jacqueline Coombe is a Research Officer at The University of Melbourne, Australia. Her research interests lie in the use of free-text comments from longitudinal health surveys as qualitative data, and in understanding issues pertaining to women's sexual and reproductive health.

Deb Loxton is Deputy Director of the Australian Longitudinal Study on Women's Health and codirector of the Research Centre for Generational Health and Ageing, University of Newcastle. She is primarily interested in those life events that impact on women's health, particularly intimate partner violence, pregnancy, and motherhood.

Leigh Tooth is Principal Research Fellow and Deputy Director with the Australian Longitudinal Study on Women's Health, based at the University of Queensland. She leads a program of research into social determinants of health and women carers. Other research interests are quality of life, and comorbidity.

Julie Byles is Director of the Research Centre for Generational Health and Ageing at the University of Newcastle, and a Director of the Australian Longitudinal Study on Women's Health. Her research interests in women's health concern factors that affect the good health of women across the life course.

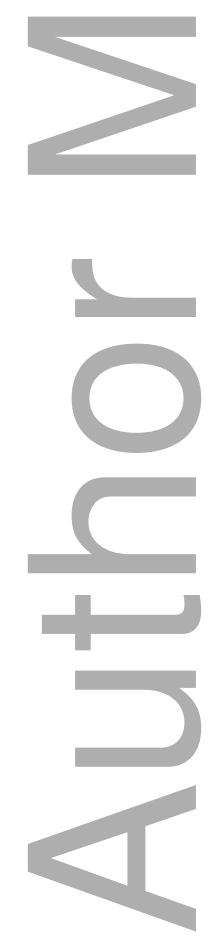


DR. JACQUELINE COOMBE (Orcid ID : 0000-0002-9520-5724)

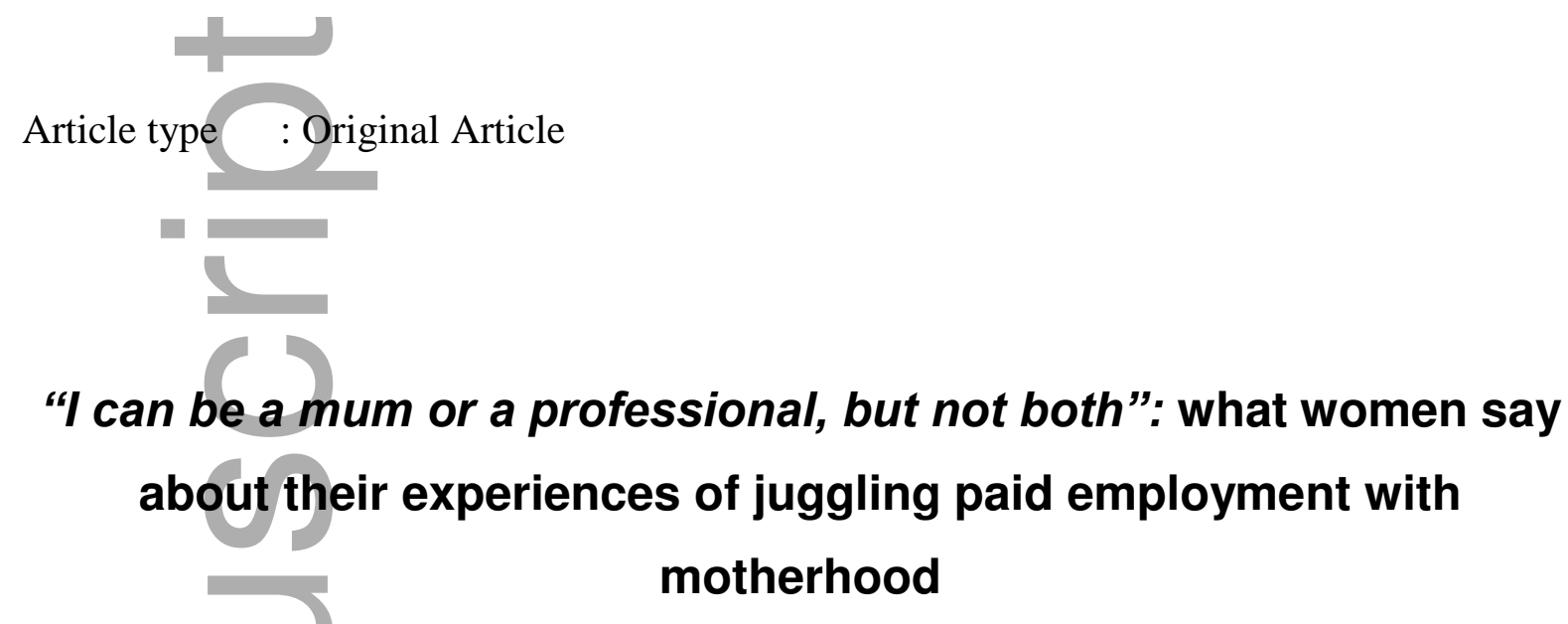

Abstract

Past research has identified the salience of the notion of 'good motherhood' in countries such as Australia, where women are expected to invest significant time and energy, often through self-sacrifice, to raise their children. We analysed free-text comments provided in response to an open-ended question from the Australian Longitudinal Study on Women's Health (ALSWH) to examine whether the discourse of 'good motherhood' played any role in how women articulate their experiences of juggling paid employment with motherhood. Eighty women from the cohort born 1973-78 were included, providing 223 comments. 'Good motherhood underpinned many of the accounts about combining motherhood with paid employment. Women reported life as stressful and hectic as they attempted to juggle the demands of childcare with paid employment and domestic chores. Although some identified 'good motherhood' as an unachievable ideal, most were largely unable to disengage with this discourse. Broader social structures, such as inflexible working conditions, were found to reinforce and support this ideal, contributing to the strength of the discourse.

Key words: motherhood, paid employment, childcare, unpaid work, social norms

\section{Introduction}

For many Australian mothers, juggling paid work and motherhood is a daily reality and an economic necessity. In 2013, the cost of raising two children from birth to 24 years in a 
middle income family in Australia was estimated at approximately $\$ 812 \quad 000$ (AMP.NATSEM, 2013), and will be higher in today's values. These costs, combined with rising costs of living (Australian Bureau of Statistics, 2017b), and high housing costs, mean that dual earning families where both adults work, are becoming increasingly common in Australia (Australian Bureau of Statistics, 2016). Indeed women are increasingly engaged in the paid workforce, with 66\% of women aged 20-74 years in 2016-2017 engaged in employment, as compared to $78 \%$ of men (Australian Bureau of Statistics, 2017a), an increase from 60\% in 2001-2002 (Australian Bureau of Statistics, 2012). Women are also far more educated today than in the past. In $201640 \%$ of women in their late twenties had achieved a Bachelor's degree or higher, as compared to $31 \%$ of men in the same age group (Australian Bureau of Statistics, 2017a).

Despite their increasing participation in the workforce in Australia, women still provide the majority of childcare (often by reducing or re-arranging their work schedules) and undertake the major share of domestic chores (Craig, 2006, Craig, 2007). Although the proportion of women with children who are employed has increased over time (from 46\% in 1996 to 53\% in 2016) (Australian Bureau of Statistics, 2018), women are still less likely to be consistently engaged in work, and far more likely to be engaged in part-time employment than men (Australian Bureau of Statistics, 2017a). In comparison, women without children are typically engaged in full-time employment (Majeed, 2016). Childcare provision is also clearly gendered; while approximately $29 \%$ of women work full-time in families where the youngest child is five or under and is in formal childcare, $90 \%$ of fathers work full-time, regardless of the type of childcare their children use (AMP.NATSEM, 2014). Further, formal childcare in Australia is expensive, costing families on average \$4352AUD per annum in 2013, approximately $4.2 \%$ of average income (AMP.NATSEM, 2014). Traditional notions of 'breadwinning' fathers and 'stay at home' mothers continue to dominate the Australian cultural landscape; arguments regarding women's return to work after children often centre on the cost of childcare negating the mother's potential income, rather than the income of the family unit as a whole (Cooklin et al., 2015).

The relationship between motherhood and employment is the subject of a significant literature base (Bianchi and Milkie, 2010), spanning from, for example, explorations of how women cope with identity transitions to motherhood and employed parent, to how women use their time to juggle childcare with paid employment (Craig and Brown, 2017, Bailey, 2000). Others have described the cultural and social expectations of motherhood, and explore the 
impact of these expectations on women's lives. Hays (1998) for example, coined the term 'intensive motherhood' where women are expected to devote significant time, energy and resources into raising children, often to the detriment of their own needs. Drawing on the work of Hays and others, Lowe (2016) highlights the dominant cultural norm in western countries such as Australia of 'maternal sacrifice', where women are expected to make personal sacrifices to maximise the health and wellness of their child or children, even before they are born. In relation to working mothers, Hays suggests that paid employment is a role women are expected to take on in addition to intensive mothering (Hays, 1998). Although women can engage or reject this discourse to varying degrees, these norms are difficult to escape, and women report feeling guilt regardless of whether they return to paid work or stay home with their children (Lowe, 2016, Lupton and Schmied, 2002). A further issue with investigating this topic is that any question about 'motherhood' or 'working mothers' might be viewed as judgemental. Because the topic of motherhood raises emotional issues from the outset, it is difficult to ask directly about paid work without inadvertently implying that women should (or should not) undertake paid work once they have children. To avoid this problem, we made use of data that were not elicited in this context.

The Australian Longitudinal Study on Women's Health (ALSWH) is a longitudinal, population based cohort study which has been collecting data on a range of topics, spanning physical and emotional health to life stages and key events, among Australian women for more than 23 years. The nationally representative sample of more than 57000 women includes four cohorts of women born: 1921-26, 1946-51, 1973-78 and 1989-95. Although primarily collecting quantitative data, at the conclusion of each survey is a space for participants to write a free-text comment in response to the question 'Have we missed anything? If you have anything else you would like to tell us, please write it in the space below'. In late 2017, there were 58, 910 free-text comments across four cohorts of women. Previous explorations of these comments demonstrated the rich and varied data spanning a wide range of topics (Tavener et al 2016). Given that many Australian women will engage in juggling paid employment with motherhood, we aimed to examine free-text comments from the ALWSH to understand if and how women with children engage in the discourse of 'good motherhood' in the context of managing paid employment with motherhood.

\section{Methods}

\section{Data}


Data for this analysis came from the Australian Longitudinal Study on Women's Health (ALSWH) Details about the ALSWH have been published elsewhere (Dobson et al., 2015). For this analysis, we focus on the free-text comments in response to the question 'Have we missed anything? If you have anything else you would like to tell us, please write it in the space below' Despite some criticisms (O'Cathain and Thomas, 2004, Garcia et al., 2004) free-text comments in response to an open-ended question are increasingly being recognised as a useful and rich source of qualitative data (Rich et al., 2013, Tavener et al., 2016, Terry and Braun, 2017). These comments have successfully been utilised to explore multifaceted and complex health experiences of women, ranging from contraceptive use to widowhood (see for example (Wigginton et al., 2016, Kennaugh et al., 2015)).

\section{Sampling frame}

We restricted this analysis to qualitative data provided by the 1973-78 cohort on their most recent survey (Survey 7 in 2015), when they were 37-42 years of age and when the women would most likely be engaging in motherhood and paid employment. At this most recent survey, the 1973-78 cohort provided 1275 comments. We selected comments based on participant's quantitative responses, a process akin to identifying a sampling frame from which the data for analysis are drawn (Tavener et al., 2016). Our sampling frame therefore included women who reported that they provide care for their or their partners children at Survey 7 (regardless of the age of their child/ren), and regardless of whether women were engaged in paid employment. (See Figure 1 for a detailed overview of participants included in the sampling frame and analysis).

\section{Figure 1. Participant inclusion}

\section{Establishing the dataset for analysis}

Comments made on Survey 7 by the women who met the quantitative inclusion criteria were exported into an excel spreadsheet. All free-text comments were read by the first author to identify those relevant to the research question. Comments were included if they mentioned being a mother, caring for their children, participating in work, or mentioned some form of leave from employment to care for their children. Of the 928 total comments made by eligible women 127 were deemed relevant. These comments were re-read by the first author to confirm they met the inclusion criteria, and that the inclusion criteria were appropriate. The second author checked the first $10 \%$ of comments to ensure the inclusion criteria were indeed 
appropriate, and also checked any other comments where the first author felt the relevance was doubtful. Only one additional comment was added to the dataset after this check resulting in 128 relevant comments made by eligible women on their most recent survey. Free text comments from the earlier surveys of the 128 women were then extracted, such that each woman could have a series of comments from each completed earlier survey, resulting in a dataset consisting of 440 comments from 128 women. The first author read through all of the data to familiarise herself with the comments, then uploaded the data to NVivo Qualitative Analysis Software (QSR International Pty Ltd, 2012). Two further comments were excluded during analysis after discussion between the first two authors, bringing the final total to 126 women with 432 comments.

\section{Analysis}

All comments were coded using a thematic analysis technique. Thematic analysis, as detailed by Braun and Clarke (2006), is a flexible analysis technique which has been successfully applied to free-text analysis (see, for example (Wigginton et al., 2016, Tavener et al., 2016)). We inductively analysed the data, sticking as close to the participant comments as possible. Key themes focused on the type of employment undertaken, type of leave, childcare arrangements, emotion, and managing multiple roles. Given our interest in how women juggle paid employment with motherhood, the latter theme (managing multiple roles) is the focus of this paper. Many women commented on the multiplicity of roles they undertake in their day-to-day lives, including childcare, motherhood, employment, housework, and being a wife for example, and we grouped these comments together under the key theme 'managing multiple roles.' Applying a discursive lens to the comments captured within this theme (80 women with 223 comments), and taking an inductive approach to coding, we then examined whether notions of 'good motherhood' were present in women's accounts of motherhood, with a particular interest in what they said about their experiences of juggling (or not juggling, as it may be) paid employment with motherhood. We looked to understand this discourse from a social constructionist perspective, analysing language and meaning as both a dynamic product and as an agent of recursive reproduction of social context (Wigginton and Lee, 2014),. In this way, we explored the individual experiences of the women in our dataset as a reflection of their broader social context, understanding how women position themselves in relation to these discourses, without the assumption that they will act in accordance with them (Willig, 2000). The results of this analysis are the focus of this paper. Quality and 
rigour in qualitative research was adhered to using the guidelines proposed by Kitto and colleagues (2008).

\section{Ethics}

The ALSWH has received ethical approval from the Australian Government Department of Health Human Research Ethics Committee and the Human Research Ethics Committees at the Universities of Queensland and Newcastle.

\section{Results}

Demographic characteristics can be found in Table 1. In brief, the women included in this analysis were largely married, had between 1 and 3 children, were engaged in paid employment, lived in a major city, and had more than a high school education. The majority also reported engaging in more than 49 hours of childcare per week. This compares to the overall cohort at Survey 7: 25\% had no children, 70\% 1-3 children and 5\% had four or more; and where approximately $47 \%$ were working full-time and around $40 \%$ were working parttime. There were few differences between eligible women who did and did not provide relevant comments, except those with comments tended to be more educated. All participant comments presented below have been de-identified and assigned a pseudonym. Information regarding number of children, relationship status and employment status at the time of the comment are also provided.

\section{Table 1. Demographic characteristics}

Notions of 'good motherhood' were found to underscore the comments from the women in our dataset, who positioned their roles as mother first and foremost, and attempted to fit the rest of their responsibilities around their perception of the mother role. Across our data, the women in our study consistently emphasised that motherhood was an all-consuming, fulltime job that demanded large quantities of their time and energy. In particular, women reported providing the majority of care to their young children, regardless of whether they engaged in paid employment or not.

Full time mother with zero spare time for exercise, reading etc. Extremely limited family support and no external child care (by choice) $=$ hard! But very satisfied with motherhood. (Jane, Survey 7, 1 child, de facto, not in paid employment)

Life is hectic raising 4 children and working part time. It is hard to find time for yourself, let alone your partner! I wouldn't be able to do what I do without the help, 
love and support of my partner and my mum! (Sonya, Survey 7, 4 children, married, paid employment)

Although not currently looking for work I am intending to go back to work next year on a part time basis during school hours (my daughter will be Year 3). I gave up work when my daughter started kindy [kindergarten] as I wanted to be available to help out at any time with class duties. Also after my 3rd ectopic pregnancy when I realised that I wouldn't have any more children I wanted to be there for her whenever she needed me as I felt that I had been unavailable for her when I was recovering from lost pregnancies and surgeries. I believe that she has benefited from this as she is a resilient, confident and caring child. (Alex, Survey 7, 1 child, married, not in paid employment)

In calling themselves full-time mothers ('Full time mother with zero spare time') and by using personal pronouns ('I wouldn't be able to do what I do' and 'I wanted to be there for her'), the women position themselves as the primary carers of their children. This is particularly clear in the second comment, where the participant emphasises that she wouldn't be able to do what she does (i.e. care for her children and work part-time) without the help, love and support of my partner and mum.' While it might be fair to say 'help' is provided by her mother, it is interesting to note that her partner also provides 'help', implying that the children are her sole responsibility as 'mother'.

Further, many of these women chose not to utilise formal childcare services in favour of providing care themselves (see the first comment), and emphasised the need to be constantly available to their children (see the third comment). Consistent with the ideal of 'good motherhood', the women positioned their role as a mother first and foremost; the other dayto-day tasks they were required to complete had to fit around their role as mother, including paid employment. In this space, the dominant discourse of 'good motherhood' is one of sacrifice ('gave up' work), singular responsibility, and devotion demonstrated through physical presence (availability 24/7). The understandable exhaustion felt by women was almost viewed as a further aspect of 'good motherhood'.

Consistent with broader demographic trends, the women in our study reported rearranging, reducing or stopping paid employment in order to care for their children.

I have taken time out of the workforce to raise my children as I do not want to put them in day care at such a young age. Motherhood is a very challenging experience 
but so rewarding. I do worry about career opportunities down the track and feel disappointed that I will almost certainly have to take a backwards step career wise when I do return to the workforce. (Kelly, Survey 7, 2 children, married, not in paid employment)

In the midst of changing jobs, hope the new one next week will be/provide better work flexibility after probationary period, therefore leading to better balance of work/life family time. (Grace, Survey 7, 2 children, married, paid employment)

I think self-esteem has a lot to do with doing what makes you proud of yourself. I was very down after having kids [children] and my hubby [husband] encouraged me to do what made me happy so I have a small handmade business (not really making money) but it makes me proud and happy. Also I can be home with kids [children] afterschool and get involved in school activities, which is so rewarding and I know a lot of mothers/kids miss out on that. Doing this survey has made me realise I need to be healthier and...how darn lucky I am in life... (Bethany, Survey 7, 2 children, married, not in paid employment)

I have just had my first child 4 weeks ago on 12 months maternity leave (14 weeks full pay) the rest unpaid. It is strange not having to go to work every day and that is something that I am still getting used to - as I have been to uni [university] to get a good job to work for good money. Now not being at that job is something that I did not think about when we planned our family. I found it difficult to answer some of these questions as my circumstances have changed so dramatically in the past month... (Samantha, Survey 4, 1 child, married, not in paid employment)

Although almost all women take some time away from paid employment to recover from pregnancy and childbirth, the above comments suggest some tension between being a 'good mother' and returning to work. Engaging in 'good motherhood', it seems, requires some sacrifice by taking 'a backwards step career wise' (the first comment), by 'changing jobs' (the second comment) for greater work flexibility, or by being unable to get involved in school activities, something that 'a lot of mothers/kids miss out on' (the third comment). Further, as evident in the third and fourth comments, some women reported difficulty in adjusting to their roles as mothers. In the third comment, the participant reports feeling 'very down after having kids' and in the fourth the participant comments about how 'strange [it is] not having to go to work every day.' As has been reported elsewhere (Lupton and Schmied, 
2002), although the women recognise that remaining at home and caring for their children is important, many also report struggling with the loss of their working identities. This could also be understood as reflective of broader sociocultural meanings ascribed to motherhood, where the 'work' undertaken by mothers is not valued in the same way as paid employment.

Indeed, this was also evident in comments from women who chose to stay at home with their children long-term (e.g. be a 'stay at home mum'). There seems to be an expectation that women will return to paid work after having children, and although women are encouraged to remain at home with their newborn babies, women who chose to remain at home in the longer term report feeling stigmatised for this decision (Lupton, 2000, Johnston and Swanson, 2006). In our dataset, women who had chosen to stay at home largely defended their choice by stressing that the work they undertake by being at home is equally as important as that undertaken within the context of paid employment.

In regards to question 95 - it asked about main occupation - although I don't work in paid employment it would be good to explain how else a parent's time is taken up, i.e. full-time mother, means 24/7!!! It would be good to have an opportunity to look at what else we achieve, apart from paid work. Keep up the good work - Thanks. (Emma, Survey 7, 4 children, married, not in paid employment)

Here, the participant emphasises that motherhood is 'full-time' and '24/7', a demand far greater than the typical 9 to 5 working day, while similarly acknowledging the value placed on paid employment. Although women remaining home with their children were more overt in their justification for doing so, most of the women contributing to this dataset, regardless of their employment status, justified their decision.

For some, the decision to not return to work after having children was directed by what they considered to be broader gendered norms in the workplace.

"There are questions about work and work life balance. My situation is that I have recently stopped paid work as I found it impossible for both my husband and myself to maintain careers and have the level of involvement in our children's lives that we wanted. The lack of flexibility in mid-level corporate jobs mean that for many people it is a choice of all (full-time) or nothing. The inability for me to maintain my career has led to dissatisfaction and worry about our financial future, especially as I am no longer financially independent. This may be outside the scope of your study. (Carolyn, Survey 7, 3 children, married, not in paid employment) 
It would be nice if you could ask about availability of employment particularly part time employment. I desperately want a job but I am in a rural area with no family and no child care available particularly for my 10 year old. Part time employment is so hard to get and, from what I hear from friends in the city, getting harder as employers seem to be moving away from offering it. [Capital city] seems to be going backwards and the rural areas never moved forwards in the first place. Women just don't seem to be welcome in the workplace any more. I find this so depressing. Makes you feel so worthless. I don't think Australians really care about families or our children. It's all about money. I had to give up my senior management role to put my family first and now I can't get a look in for anything because I can't work full time. It seems I can be a mum or a professional but not both. Why are women still cornered into this type of decision? (Hannah, Survey 7, 2 children, married, in paid employment)

In both of the above comments, the women point to social norms regarding employment that are preventing a return to work, namely the availability of flexible and part-time working conditions. In the second comment, the participant points to the difficulties in being both a mother and paid employee, suggesting that she can 'be a mum or a professional but not both.' She goes onto question why women are required to make a choice between motherhood and a career, and both emphasise their dissatisfaction in not being able to find flexible employment. In line with notions of 'good motherhood' the women in our dataset largely positioned their decisions to rearrange, reduce or stop paid employment as the only choice they could have made; there was little or no implication that it was a choice made with her husband or partner, or that her husband or partner would remain home with the children and she return to work. (In the one comment that did report reversed gender roles, the participant nevertheless still emphasised the amount of childcare and housework she was still required to undertake). Lyn (Craig, 2006) suggests that society has experienced 'half a sex revolution' where women have largely changed their behaviour, by increasing their participation in the workforce and reducing time spent doing housework, while men have largely not altered their behaviour (i.e. by undertaking a greater share of household duties). Although stay at home fathers are an increasing phenomenon in Australia (see for example (Stevens, 2015)), women are largely expected to provide full-time care to their children themselves, by arranging the help of others or by sacrificing their paid work income on formal childcare.

In addition to providing childcare, the women also reported undertaking the majority of the domestic chores. This is consistent with the broader literature which suggests that women 
regularly undertake the majority of housework, regardless of whether or not they also engage in paid employment (Craig, 2006).

I am very happy with my life - although I would like to slow it down a little and have more time to spend with my family and to exercise and relax. I am currently working 2 jobs and my husband is FIFO [fly in, fly out] so there are times when I feel absolutely knackered. I, and many others, still face inequalities in the workplace particularly when it comes to having career interruptions. I feel like I am mainly responsible for the day to day household running and the kids extracurricular and school activities. This is mostly because my husband works away, but it does still impact on my health and wellbeing as it does get quite stressful. This being said, in general I feel I am very lucky to have three healthy kids, a loving partner, a house to live in and the opportunity to still participate in my career. (Fiona, Survey 7, 3 children, de facto, in paid employment)

Sometimes very difficult to achieve work/life/work/family life balance when partner does fifo [fly in, fly out] work. Increased tiredness and decreased free time when single parenting when partner at work. Difficult to maintain old gold friendships when moved interstate with partner and miss regular time with own family grew up with can place increased stress on life and relationships [sic]. Thank you this survey also makes me realise how to really appreciate the life I have created for myself now and highlights what I can improve. (Sue, Survey 7, 1 child, de facto, in paid employment)

In both of the above comments, the women emphasise how difficult they are finding work/life balance, and their exhaustion at managing multiple demands at once. In the first comment, the participant notes how she is 'mainly responsible for the day to day household running' and the impact this has on her own health and wellbeing, while similarly excusing her husband from these demands because of his work schedule (fly in, fly out; where the employee must travel a significant geographical distance to their place of work, usually in a remote location, often for a fixed number of days or weeks (Australian Government Australian Institute of Family Studies, 2014)). In both comments, the women demonstrate what Lowe (Lowe, 2016) terms 'maternal sacrifice', undertaking the multitude of tasks expected of them as 'good mothers' while neglecting their own self-care in order to fit everything in. 
While the comments in our dataset were largely oriented towards quite traditional gendered roles, where women care for children and men support the family financially, there were a small number of comments that emphasised that both the participant and her husband shared childcare equally. Although these comments still emphasised the importance of constant parental care for their children, this care appeared to be more equally shared.

My husband and I are self-employed and work very hard. My husband and I juggle work and childcare, we have the luxury of always being there for our kids and not using any form of childcare. When we are with the kids, we are truly connected to them. We surf together, play board games, watch movies, I coach my daughter's netball team and manage my son's soccer. We do museums and bake cakes. The flip side is that we often work into the night and weekends. Any holidays we take still require remote work. We haven't had a true break from the business (i.e. one where we weren't checking emails and making calls or discussing plans late at night) for over 10 years. Consequently we are exhausted and are currently in the middle of selling the business. Despite the challenges, I am very happy. We recognise that we have far more than others. I have excellent relationships with my husband, my children and my exceptional friends. Exhausted, yes. Blessed, absolutely. (Debra, Survey 7, 2 children, husband, in paid employment)

However, despite sharing care with her husband, the participant still reported stress and exhaustion in juggling childcare and paid employment, and simultaneously, stresses the importance of ensuring that she and her husband are 'always...there for our kids' and not utilising formal childcare. Moreover, this comment also demonstrates the idea that children should be cared for by a parent rather than, for example, a childcare worker, a norm which underscores the traditional division of household labour (e.g. one parent remains home to care for the child or children, while the other engages in paid employment). This norm, which is particularly prevalent in Australia, is addressed in further detail in the discussion.

\section{Discussion}

Overall, many of the women in our dataset positioned their role as mother in relation to the notion of 'good motherhood', ensuring that their children received as much care and attention as they could give by shifting their paid employment and other activities around their motherhood role. The women reported being primarily responsible for childcare and domestic activities, while their partners or husbands continued to engage in paid employment. 
Although some recognised 'good motherhood' to be an unachievable ideal, there appeared to be little they could do to disengage with this discourse, particularly when broader social structures, such as inflexible working conditions, reinforced this discourse. In the few instances when the women did manage to subvert these social norms by actually sharing childcare with her partner or husband, often by engaging in non-traditional paid work by working in their own small businesses, the demands of 'good motherhood' did not appear to diminish. Conceptualisations of being a 'good mother' consistently underpinned the stresses of combining motherhood with work, where the women constantly reported feeling stressed, tired and busy as they tried to juggle being a 'good mother' with employment.

Past research has clearly demonstrated the link between idealised notions of 'good motherhood' and maternal mental health. Women who internalise the 'good motherhood' ideal and who feel that they do not meet this ideal experience guilt and shame, and have been shown to be ultimately at greater risk of depression (Liss et al., 2013). In another study, believing that mothers provide the best care for children, and that motherhood is challenging, were also associated with negative maternal mental health (Rizzo et al., 2013). Others have shown the pervasiveness of the 'good motherhood' discourse and its impact on maternal mental health, regardless of whether women ascribe to this discourse or not (Henderson et al., 2016). 'Good motherhood' requires women to invest significant time and energy into their children and, typically, remain at home to care for them (Hays, 1998). However dual career families are increasingly common in Australia, with women returning to paid employment after having children. Although maternal employment has been shown to be associated with fewer symptoms of depression (Gjerdingen et al., 2014), and a return to work important in regaining an identity beyond motherhood (Lupton and Schmied, 2002), 'good motherhood' is not necessarily compatible with paid employment and women report difficulty and stress in managing the demands of motherhood with paid work, as was clearly evident in our study. Further, mothers who engage in paid employment report experiencing significant time pressure (Rose, 2017, Otterbach et al., 2016), while women who choose to remain at home with their children long term report experiencing loneliness and isolation (Johnston and Swanson, 2006). In one study, women who engaged in part-time employment appeared to manage the stress of motherhood and employment better than their full-time and stay-athome counterparts (Johnston and Swanson, 2006), although this option may not be available to all women and, regardless, reinforces the notion that women should make career sacrifices to care for their children and thus aspire to 'good motherhood'. 
Our results also suggest persistent gendered norms when it comes to parenthood and providing care for children, despite social changes over the past decades that have seen increasingly egalitarian roles in Australia. In a study comparing time-use in five countries (Australia, Italy, France, Denmark and the United States), the authors found that while men and women typically have equal opportunity in regards to education and employment prior to parenthood in Australia, the division of labour becomes clearly gendered after having children (Craig and Mullan, 2010). In particular, finding significant differences between parental time use in Australia and the US compared with Denmark and France, the authors suggest that social norms regarding the importance of constant parental care (rather than the use of other formal care services), and social policies reinforcing traditional gender roles in the household, influence these trends (Craig and Mullan, 2010). In Denmark, for example, gender equality in unpaid (i.e. domestic) work is generally socially accepted, there are policies encouraging fathers to participate in childcare and there is institutional support for mothers to return to work (Craig and Mullan, 2010). Although Australian and Danish fathers provided similar amounts of childcare in the aforementioned study, the gap in time use was primarily due to Danish mothers providing less childcare than Australian mothers, instead sharing care with fathers and formal childcare providers (Craig and Mullan, 2010). Moreover, in a cross-national study of 19 countries (including Australia) examining the role of cultural context and work-family policy conditions in maternal employment, the authors conclude that cultural and policy context significantly impact maternal employment in the countries examined (Boeckmann et al., 2015). In countries where use of formal childcare and maternal employment are viewed favourably, mothers experience fewer employment disruptions, including long periods of time away from paid employment, thus avoiding the inherent consequences of these long absences (Boeckmann et al., 2015). The benefits of attending formal, centre-based childcare for children during their first three years of life have also been demonstrated (Gomajee et al., 2018).

In 2018, the Australian government introduced a new childcare scheme, simplifying the existing system and 'supporting parents into work' (Australian Government Department of Education and Training, 2017). Replacing the current Child Care Benefit and Rebate, the new Child Care Subsidy provides greater assistance to low and middle income families, with families earning less than approximately \$67,000AUD per year receiving an $85 \%$ subsidy on their childcare fees, as long as they meet the eligibility criteria (Australian Government Department of Education and Training, 2017). Although reducing barriers to childcare 
services is important, as we have shown, the discourse of 'good motherhood' continues to underscore women's explanations of mothering and significant cultural change is needed to truly meet this aim. On a cultural level, the discourse of 'good motherhood' underpins workplace norms, where women regularly engage in part-time employment after having children, while men continue to fulfil the 'breadwinner' role. This not only impacts the options for women returning to paid employment, but also limits those opportunities afforded to men who may wish to stay home to care for their children. These gendered norms are clearly evident in the Australian Government's Paid Parental Leave Scheme where this leave automatically defaults to the mother (McCurdy and Knell, 2015). Further, although women are entitled to 18 weeks of paid leave, fathers are only eligible for 2 weeks, unless the mother elects the father as the primary carer and transfers her paid parental leave to him (Australian Government Department of Human Services, 2018). In a 2010 study comparing parental leave policies in 21 high income countries, Australia was found to be one of the least gender equitable of those examined (Ray et al., 2010). Paid maternity leave is, of course, essential in allowing women to take time out of work when they have a new baby. However, there is clearly much work to be done in order to redefine persistent gendered norms (and by extension, allowing women to make decisions about returning to paid employment - or not after having children without the pressure of 'good motherhood'), including the provision of low cost and flexible childcare services, reducing the gendered pay gap, ensuring men are able to access paternity leave in order to care for their children, and shifting social norms around gendered roles in the home.

\section{Strengths and limitations}

Open-ended questions provide space for participants to write about issues salient to their own lives, in their own words and from their own 'sense making frameworks' (Terry and Braun, 2017), and the resultant free-text comments typically provide deep and valuable insights into the experiences participants share (Tavener et al., 2016, Rich et al., 2013). In our study, participants were asked to respond to a general, open-ended question asking if we had forgotten anything, or if there was anything else they would like to tell us, and those included in this analysis wrote specifically about the struggle of juggling multiple roles and being a 'good mother'. That these responses were unsolicited, and that many of these comments were about the juggle motherhood involves, suggests the ubiquity of this experience for the women in our study. Limitations of our study primarily lie in its small sample size and lack of generalisability to the broader population. In particular, our sample was largely well educated 
and in married or de facto relationships; their experiences may not be reflective of those of single mothers, or women with diverse socioeconomic backgrounds, for example. One further issue relates to sample selection, whereby we did not use all of the survey responses from the past 23 years to identify relevant comments but chose instead to select our sample using the most recent survey. In this way we were able to capture women who had children at varying stages of their lives, while exploring issues that were most relevant in current times. However, this approach may have resulted in missed issues that were relevant in the past. As an exploratory study interested in examining the experiences of women in their own words, generalisability was not our intention. Our findings should be considered within the context of these limitations.

\section{Conclusion}

In conclusion, our findings demonstrate how notions of 'good motherhood' underpin Australian women's comments about engaging in paid employment and being a mother, regardless of the age of the child, or the degree of women's workforce attachment. The women in our study positioned themselves as engaging in the majority of the childcare duties and housework, as well as engaging in paid employment, and emphasised the stress and difficulty these often competing roles entailed. Our work suggests there remains much to be done in shifting gendered norms around not only what it means to be a good mother, but also around roles in the home and workplace.

\section{References}

AMP.NATSEM. 2013. Cost of Kids: The cost of raising children in Australia [Online]. http://www.natsem.canberra.edu.au/storage/AMP_NATSEM_33.pdf AMP.NATSEM. 2014. Income and Wealth Report Issue 35 - Childcare Affordability in Australia [Online]. http://www.natsem.canberra.edu.au/publications/?publication=ampnatsem-incomeand-wealth-report-issue-35-childcare-affordability-in-australia

Australian Bureau of Statistics. 2012. 4125.0 - Gender Indicators, Australia, Jul 2012 [Online].

http://www.abs.gov.au/ausstats/abs@.nsf/Lookup/4125.0main+features1110Jul\%202 $\underline{012}$ 
Australian Bureau of Statistics. 2013. 4125.0 - Gender Indicators, Australia, Jan 2013

[Online].

http://www.abs.gov.au/ausstats/abs@.nsf/Lookup/by\%20Subject/4125.0 Jan\%20201

3 Media\%20Release Aussie\%20mums\%20by\%20numbers\%20(Media\%20Release) $\underline{\sim 6153}$

Australian Bureau of Statistics. 2016. 2016 Census QuickStats Australia [Online].

http://www.censusdata.abs.gov.au/census_services/getproduct/census/2016/quickstat/ $\underline{036}$

Australian Bureau of Statistics. 2017a. 4125.0 - Gender Indicators, Australia, Sep 2017

[Online].

http://www.abs.gov.au/ausstats/abs@.nsf/Lookup/by\%20Subject/4125.0 Sep\%20201

7 Main\%20Features Economic\%20Security 4

Australian Bureau of Statistics. 2017b. 6530.0 - Household Expenditure Survey, Australia:

Summary of Results, 2015-16 [Online].

http://abs.gov.au/ausstats/abs@.nsf/Latestproducts/6530.0Main\%20Features12015-

16 ? opendocument $\&$ tabname $=$ Summary $\&$ prodno $=6530.0 \&$ issue $=2015-$

$16 \&$ num $=\& v i e w=$

Australian Bureau of Statistics. 2018. Happy Mother's Day from the ABS! [Online].

https://www.abs.gov.au/AUSSTATS/abs@.nsf/mediareleasesbyReleaseDate/168BFD A0C45F98A8CA258288001A58C5?OpenDocument

Australian Government Australian Institute of Family Studies. 2014. Fly-in fly-out workforce practices in Australia: The effects on children and family relationships [Online].

https://aifs.gov.au/cfca/publications/fly-fly-out-workforce-practices-australia-

effects/history-and-definitions

Australian Government Department of Education and Training. 2017. New Child Care

Package - families (from 2 July 2018) [Online]. https://www.education.gov.au/newchild-care-package-families-2-july-2018

Australian Government Department of Human Services. 2018. Parental Leave Pay [Online]. https://www.humanservices.gov.au/individuals/services/centrelink/parental-leave-pay

Bailey, L. 2000. Bridging Home and Work in the Transition to Motherhood: A Discursive Study. European Journal of Women's Studies, 7 (1), 53-70.

Bianchi, S. M., Milkie, M. A. 2010. Work and Family Research in the First Decade of the 21st Century. Journal of Marriage and Family, 72 (3), 705-725.

This article is protected by copyright. All rights reserved 
Boeckmann, I., Misra, J., Budig, M. J. 2015. Cultural and Institutional Factors Shaping Mothers' Employment and Working Hours in Postindustrial Countries. Social Forces, 93 (4), 1301-1333.

Braun, V., Clarke, V. 2006. Using thematic analysis in psychology. Qualitative Research in Psychology, 3 (2), 77-101.

Cooklin, A. R., Westrupp, E., Strazdins, L., Giallo, R., Martin, A., Nicholson, J. M. 2015. Mothers' work-family conflict and enrichment: associations with parenting quality and couple relationship. Child: Care, Health and Development, 41 (2), 266-277.

Craig, L. 2006. Children and the revolution: A time-diary analysis of the impact of motherhood on daily workload. Journal of Sociology, 42 (2), 125-143.

Craig, L. 2007. How Employed Mothers in Australia Find Time for Both Market Work and Childeare. Journal of Family and Economic Issues, 28 (1), 69-87.

Craig, L., Brown, J. E. 2017. Feeling Rushed: Gendered Time Quality, Work Hours, Nonstandard Work Schedules, and Spousal Crossover. Journal of Marriage and Family, 79 (1), 225-242.

Craig, L., Mullan,K. 2010. Parenthood, Gender and Work-Family Time in the United States, Australia, Italy, France, and Denmark. Journal of Marriage and Family, 72 (5), 13441361.

Dobson, A. J., Hockey, R., Brown, W. J., Byles, J. E., Loxton, D. J., McLaughlin, D. P., Tooth, L. R., Mishra, G. D. 2015. Cohort Profile Update: Australian Longitudinal Study on Women's Health. International Journal of Epidemiology.

Garcia, J., Evans, J., Reshaw, M. 2004. “'Is There Anything Else You Would Like to Tell Us" - Methodological Issues in the Use of Free-Text Comments from Postal Surveys. Quality and Quantity, 38 (2), 113-125.

Gjerdingen, D., McGovern, P., Attanasio, L., Johnson, P. J., Kozhimannil, K. B. 2014. Maternal Depressive Symptoms, Employment, and Social Support. The Journal of the American Board of Family Medicine, 27 (1), 87-96.

Gomajee, R., El-Khoury, F., Côté, S., van der Waerden, J., Pryor, L., Melchior, M. 2018. Early childcare type predicts children's emotional and behavioural trajectories into middle childhood. Data from the EDEN mother-child cohort study. Journal of Epidemiology and Community Health, 72 (11), 1033.

Hays, S. 1998. The Cultural Contradictions of Motherhood, Yale University Press. 
Henderson, A., Harmon, S., Newman, H. 2016. The Price Mothers Pay, Even When They Are Not Buying It: Mental Health Consequences of Idealized Motherhood. Sex Roles, 74 (11), 512-526.

Johnston, D., Swanson, D. 2006. Constructing the "Good Mother": The Experience of Mothering Ideologies by Work Status. Sex Roles, 54 (7-8), 509-519.

Kennaugh, R., Byles, J., Tavener, M. 2015. Beyond widowhood: Do prior discovered themes that describe the experiences of older Australian widowed women persist over time? Women \& Health, 56 (7), 1-16.

Kitto, S. C., Chesters, J., Grbich, C. 2008. Quality in qualitative research. Medical Journal of Australia, 188 (4), 243-6.

Liss, M., Schiffrin, H. H., Rizzo, K. M. 2013. Maternal Guilt and Shame: The Role of Selfdiscrepancy and Fear of Negative Evaluation. Journal of Child and Family Studies, 22 (8), 1112-1119.

Lowe, P. 2016. Reproductive Health and Maternal Sacrifice, London, Palgrave Macmillan.

Lupton, D. 2000. 'A love/hate relationship': the ideals and experiences of first- time mothers. Journal of Sociology, 36 (1), 50-63.

Lupton, D., Schmied, V. 2002. "The right way of doing it all”: First-time Australian mothers' decisions about paid employment. Women's Studies International Forum, 25 (1), 97 107.

Majeed, T. 2016. Workforce participation patterns over the life course and the association with chronic diseases - A gendered approach. Doctor of Philosophy (Gender and Health) Doctoral dissertation, University of Newcastle, Australia.

McCurdy, S., Knell, C. 2015. Deliberative democracy or democratic dilemma?: The curious case of Australia's statutory parental leave policy. Communities, Children and Families Australia, 9 (2), 5-22.

O'Cathain, A., Thomas, K. 2004. "Any other comments?" Open questions on questionnaires a bane or a bonus to research? BMC Medical Research Methodology, 4 (1), 25.

Otterbach, S., Tavener, M., Forder, P., Powers, J., Loxton, D., Byles, J. 2016. The effect of motherhood and work on women's time pressure: A cohort analysis using the Australian Longitudinal Study on Women's Health. Scandinavian Journal of Work, Environment \& Health, (6), 500-509.

QSR International Pty Ltd 2012. NVivo qualitative data analysis software. Version 10 ed.: QSR International Pty Ltd. 
Ray, R., Gornick, J., C. , Schmitt, J. 2010. Who cares? assessing generosity and gender equality in parental leave policy designs in 21 countries. Journal of European Social Policy, 20 (3), 196-216.

Rich, J. L., Chojenta, C., Loxton, D. 2013. Quality, Rigour and Usefulness of Free-Text Comments Collected by a Large Population Based Longitudinal Study-ALSWH. PloS One, 8 (7)

Rizzo, K. M., Schiffrin, H. H., Liss, M. 2013. Insight into the Parenthood Paradox: Mental Health Outcomes of Intensive Mothering. Journal of Child and Family Studies, 22 (5), 614-620.

Rose, J. 2017. "Never enough hours in the day": Employed mothers' perceptions of time pressure. Australian Journal of Social Issues, 52 (2), 116-130.

Stevens, E. 2015. Understanding discursive barriers to involved fatherhood: the case of Australian stay-at-home fathers. Journal of Family Studies, 21 (1), 22-37.

Tavener, M., Chojenta, C., Loxton, D. 2016. Generating qualitative data by design: the Australian Longitudinal Study on Women's Health qualitative data collection. Public Health Research \& Practice, 26 (3).

Terry, G., Braun, V. 2017. Short but often sweet: The surprising potential of qualitative survey methods. In: BRAUN, V., CLARKE, V. \& GRAY, D. (eds.) Collecting Qualitative Data. Melbourne, Australia: Cambridge University Press.

Wigginton, B., Harris, M. L., Loxton, D., Lucke, J. C. 2016. A qualitative analysis of women's explanations for changing contraception: the importance of noncontraceptive effects. Journal of Family Planning and Reproductive Health Care, 42 (4), 1-7.

Wigginton, B., Lee, C. 2014. "But I Am Not One to Judge Her Actions": Thematic and Discursive Approaches to University Students' Responses to Women Who Smoke While Pregnant. Qualitative Research in Psychology, 11 (3), 265-276.

Willig, C. 2000. A Discourse-Dynamic Approach to the Study of Subjectivity in Health Psychology. Theory \& Psychology, 10 (4), 547-570. 
Table 1 Demographic characteristics of women included in analysis versus those who met inclusion criteria but did not provide a relevant comment for this analysis

\begin{tabular}{|c|c|c|}
\hline r & $\begin{array}{l}\text { Women included in } \\
\text { analysis }(n=80)\end{array}$ & $\begin{array}{l}\text { Women who met inclusion } \\
\text { criteria but did not provide } \\
\text { a relevant comment ( } \mathrm{n}=848 \text { ) }\end{array}$ \\
\hline Age (mean, SD) & $39.94,1.45$ & $39.69,1.51$ \\
\hline \multicolumn{3}{|l|}{ Area of Residence (ARIA+) (\%) } \\
\hline missing & 7.5 & 4.72 \\
\hline Major Cities & 60 & 55.9 \\
\hline Regional/Remote/Rural & 32.5 & 39.39 \\
\hline \multicolumn{3}{|l|}{ Highest Education (\%) } \\
\hline missing & 0 & 0.71 \\
\hline No formal qualifications & 1.25 & 0.94 \\
\hline Year $10 /$ Year 12 or equivalent & 5 & 13.68 \\
\hline Trade/apprenticeship/certificate or diploma & 17.5 & 25.47 \\
\hline University degree (incl. higher degrees) & 76.25 & 59.2 \\
\hline \multicolumn{3}{|l|}{ Employment - hours paid work per week (\%) } \\
\hline missing & 0 & 0 \\
\hline not in labour force / unemployed & 17.5 & 19.69 \\
\hline employed and not paid ${ }^{\S}$ & 15 & 7.67 \\
\hline $1-15 \mathrm{hrs} p / \mathrm{w}$ & 16.25 & 12.38 \\
\hline $16-24 \mathrm{hrs} \mathrm{p} / \mathrm{w}$ & 15 & 18.04 \\
\hline $25-34 \mathrm{hrs} \mathrm{p} / \mathrm{w}$ & 15 & 14.98 \\
\hline $35-40 \mathrm{hrs} \mathrm{p} / \mathrm{w}$ & 11.25 & 14.62 \\
\hline $41-48 \mathrm{hrs} \mathrm{p} / \mathrm{w}$ & 5 & 8.73 \\
\hline $49+\mathrm{hrs} p / \mathrm{w}$ & 5 & 3.89 \\
\hline Number of children (\%) & & \\
\hline
\end{tabular}

This article is protected by copyright. All rights reserved 


\begin{tabular}{|c|c|c|}
\hline missing & 0 & 0 \\
\hline 0 & 2.5 & 4.13 \\
\hline $1-3$ & 86.25 & 87.62 \\
\hline $4+\quad-1+5$ & 11.25 & 8.25 \\
\hline \multicolumn{3}{|c|}{ Childcare - hours spent engaging in childcare per week (\%) } \\
\hline missing & 0 & 0 \\
\hline $1-15 \mathrm{hrs} \mathrm{p} / \mathrm{w}$ & 5 & 9.43 \\
\hline $16-24 \mathrm{hrs} \mathrm{p} / \mathrm{r}$ & 6.25 & 9.55 \\
\hline $25-34 \mathrm{hrs} \mathrm{p} / \mathrm{w}$ & 17.5 & 10.14 \\
\hline $35-40 \mathrm{hrs} \mathrm{p} / \mathrm{u}$ & 6.25 & 7.55 \\
\hline $41-48 \mathrm{hrs} \mathrm{p} / \mathrm{w}$ & 6.25 & 7.08 \\
\hline $49+\mathrm{hrs} \mathrm{p} / \mathrm{w}$ & 58.75 & 56.25 \\
\hline \multicolumn{3}{|l|}{ Marital status (\%) } \\
\hline missing & 0 & 0.47 \\
\hline Never married & 1.25 & 3.54 \\
\hline Married & 85 & 77.36 \\
\hline De facto & 7.5 & 11.08 \\
\hline Separated/Divorced/Widowed & 6.25 & 7.55 \\
\hline
\end{tabular}

${ }^{\S}$ Including working in the family business, farming, etc. 


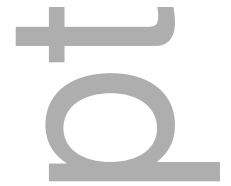

Authors read all 928 comments to check for relevance to research question (juggling paid employment with motherhood)

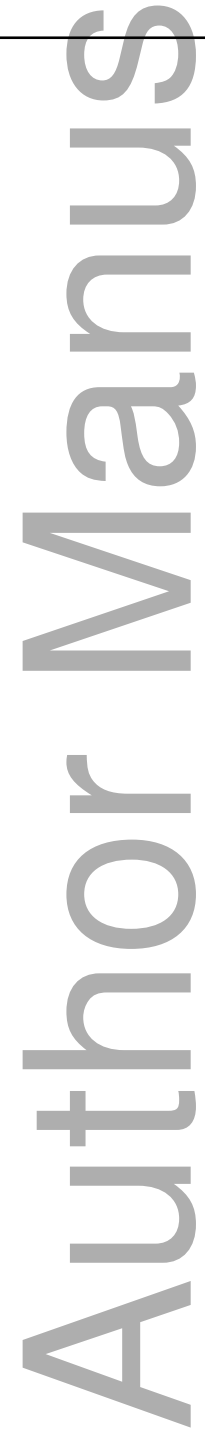

7186 completed Survey 7

1275 women completed

Survey 7 and provided a free-text comment

928 women completed Survey 7 , provided a comment, and reported providing care to their/ their partners child/ren comments relevant to the research question

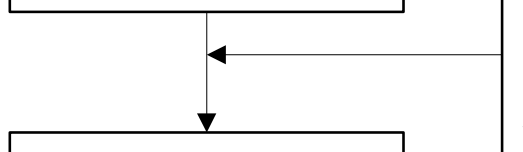

Authors re-read comments to check all relevant comments are included. An extra participant was added after discussion between the authors at this stage

128 women included in the sampling frame

440 longitudinal comments added to the dataset, such that each women would have a series of comments from each completed survey

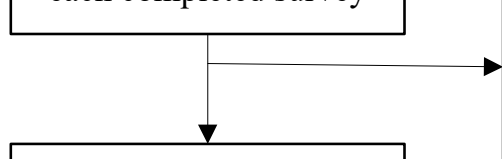

126 women with 432 comments between them now in dataset.

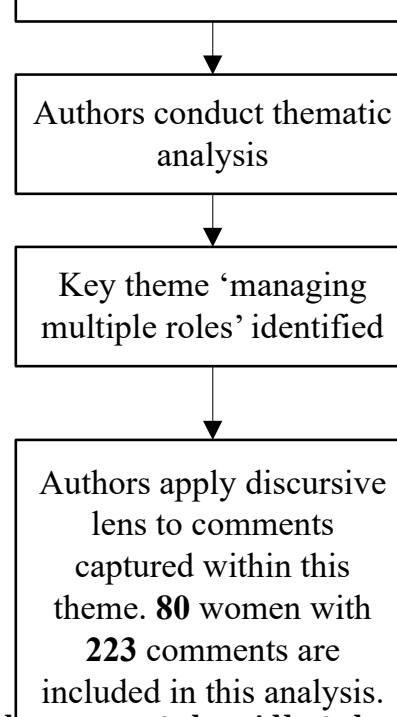

This article is protected bycopyright. All rights reserved

Authors read all comments. Two participants were excluded after discussion between the authors at this stage 


\section{University Library}

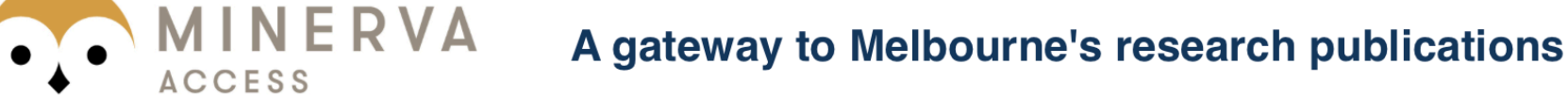

Minerva Access is the Institutional Repository of The University of Melbourne

Author/s:

Coombe, J;Loxton, D;Tooth, L;Byles, J

Title:

"I can be a mum or a professional, but not both": What women say about their experiences of juggling paid employment with motherhood

Date:

2019-09-01

\section{Citation:}

Coombe, J., Loxton, D., Tooth, L. \& Byles, J. (2019). "I can be a mum or a professional, but not both": What women say about their experiences of juggling paid employment with motherhood. AUSTRALIAN JOURNAL OF SOCIAL ISSUES, 54 (3), pp.305-322. https:// doi.org/10.1002/ajs4.76.

Persistent Link:

http://hdl.handle.net/11343/286911 